\begin{tabular}{|c|c|c|}
\hline $\operatorname{INF}_{P \cup B L|C A| N}$ & $\begin{array}{l}\text { International Journal of Advanced Engineering, Management and } \\
\text { Science (IJAEMS) } \\
\text { Peer-Reviewed Journal } \\
\text { ISSN: } 2454-1311 \text { / Vol-8, Issue-1; Jan, } 2022 \\
\text { Journal Home Page: https://ijaems.com/ } \\
\text { Article DOI: https://dx.doi.org/10.22161/ijaems.81.1 }\end{array}$ & 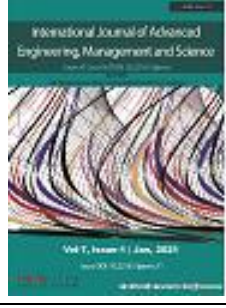 \\
\hline
\end{tabular}

\title{
Review on the Seismic performance of Steel Beam connected to Box Column
}

\author{
Mohamed G. Abdolwahab ${ }^{1}$, Ahmed H. Yousef ${ }^{2}$ and Ehab H. Ahmed ${ }^{3}$
}

\begin{abstract}
${ }^{1}$ Research Student, Structural Engineering Department, Faculty of Engineering, Ain Shams University, Cairo, Egypt. Assistant Lecturer, Construction Engineering Department., Faculty of Engineering, Egyptian Russian University, Cairo, Egypt. ${ }^{2}$ Professor of Steel Structures and Bridges, Structural Engineering Department, Faculty of Engineering, Ain Shams University, Cairo, Egypt.

${ }^{3}$ Professor of metallic constructions, Structures and metallic constructions, Research Institute Housing and Building, National Research Center
\end{abstract}

Received: 03 Dec 2021; Received in revised form: 06 Jan 2022; Accepted: 14 Jan 2022; Available online: 25 Jan 2022

\begin{abstract}
This paper presents a review on the seismic performance of steel beam connected to box column. The strength and deformation capacity of structural elements are influenced by their cumulative damages received through load cycles. Several researchers have been studying the behaviour of seismic performance of steel beam connected to box column filled with concrete but due to its complex behaviour yet it is not completely understood, where the international design standards and specifications are limited to the $\mathrm{H}$ shaped columns. The rotational capacity and dissipated energy of the welded and bolted connections are discussed. The local responses for stress and strain in the vicinity of welded and bolted joints are also investigated.
\end{abstract}

Keywords-Seismic performance, Box columns, Cyclic loading, Moment connections.

\section{INTRODUCTION}

Box-columns have higher stiffness and torsional strength in comparison with the H-shaped columns. Also, having a more substantial cross-sectional area and taking advantage of the flame-resistant fibers, these columns can exhibit better resistance to fire relative to the $\mathrm{H}$-shaped columns. The reinforced concrete-filled box-columns have a good axial strength; therefore, in the buildings that need higher axial strength, the box-columns have a widespread application and have suitable seismic performance subjected to cyclic loading. The properties of box-columns have made them ideal for the steel moment frames; recently, their seismic performance has noticed the researchers' attention.

\section{PREVIOUS STUDIES}

The practice of utilizing reduced beam section (RBS) connections was among the first remedies after the Northridge earthquake in 1994; however, the first suggestion to use the RBS connections dates back before that earthquake. Forcing the plastic hinge away from the column face, the RBS connections are used to improve the seismic behavior of moment-resisting connections (Plumier 1990) [1]. The application of this type of connection and the concept of beam weakening was investigated both numerically and experimentally in several studies. Due to the concentration of plastic strains in the weakened area, the reduction in the probability of failure in the beam flange's penetration weld to the column flange has been observed in several studies. Both the region of plasticity and plastic strains remain within the beam and do not spread into the connection area or the panel zone. Besides, the weakened RBS, which is close to the column face, performs such that the lowest moment demand is transferred to the beam end and, as a result, to the column.

Yu et al. (1999) [2] studied the effects of loading history on RBS moment connections' performance. In their study, four full-scale RBS connection samples in H-shaped columns were subjected to both basic and near-field SAC 
loading protocols until reaching failure. All samples tested with the near-field loading protocol reached the plastic rotation of $0.05 \mathrm{rad}$, and therefore they described the performance of their connections as desirable.

Pachoumis et al. (2009) [3] conducted experimental and numerical studies on RBS connections designed based on HEA profiles. They ultimately provided the rules and conditions needed to improve the performance of these connections for European profiles, aimed to meet the qualifying criteria of the codes.

Sophianopoulos and Deri (2011) [4] reviewed the parameters that affect seismic response and designing the RBS connections in special moment frames (SMF). They also provided recommendations for the design of the RBS connections in the European profiles.

Hong (2019) [5] investigated the cyclic seismic behavior of the RBS moment connection in sloping beams subjected to the SAC loading protocol Their results indicate that the maximum allowable slope of the beam to achieve proper seismic performance is 10 degrees. In the experimental study, Lee et al. (2019) [6] evaluated the cyclic seismic performance around the RBS moment connection's weak axis. Their study's experimental specimen had a strength degradation of less than $20 \%$ of the beam's bending capacity at the inter-story drift angle of $0.04 \mathrm{rad}$. They also proposed some recommendations for the weld access hole's size beneath the butt joint between the beam flange and the horizontal continuity plate. It should be noted that many studies on RBS connections provided in the literature have been based on wide-flange columns (Engelhardt et al. (1998) [7], (2000) [8]; Gilton et al. (2000) [9]; Iwankiw (2004) [10]; Kim et al. (2016) [11]), and attention to the seismic performance of this connection in box-columns has been negligible.

At the time of the Northridge earthquake, the existing welded unreinforced flange-welded web (WUF-W) moment connections had a poor performance. One of the weaknesses of those connections prior to the Northridge earthquake was the lack of engagement of the bolted web in the transfer of beam moment and shear to the column. Through various numerical and experimental studies, along with making several changes in the design and construction details, today, a WUF-W connection is considered as a prequalified connection with respect to steel seismic design codes. Unlike the RBS connection, the plastic hinge in the WUF-W connection is not promoted away from the column face. Thus, the connection is designed to meet the special moment frame criteria and control the connection failure. It is worth noting that the failure in this connection is controlled through detailing related to the welding of the beam flange to the column flange, welding of the beam web to the column flange, as well as the shape and weld access hole geometry (AISC/ANSI 360-16 2016b) [12]. Han et al. (2016) [13] Investigated the cyclic seismic performance of the WUF-W moment connection. By examining the rupture index parameter in finite element (FE) models, they have mentioned the slope of access holes as an effective factor in the WUF-W moment connection's cyclic seismic behavior. Changes in the access holes' geometry have also been effective in the distribution of the stress and strain near the access holes. Shin and Kim (2017) [14] assessed the seismic performance of WUF-W and WUF-B moment connections in H-shaped columns using the SAC loading protocol; the connections met the qualification suitably criteria of the code. They compared the rotation capacity and energy of connections as well as local stress-strain responses near the column. In that study, the rotation capacity and energy of the WUF-W connection were more than those for the WUFB connection; moreover, the WUF-W connection's failure occurred at higher drifts compared to the WUF-B connection. They also proposed a new model to reduce simulation time costs, which was properly adapted to the experimental results.

An important issue nowadays is using the I-beam to box-column (IBBC) connections, which is widely practiced internationally. Although the international design standards and specifications are limited to the H-shaped columns, based on few test data and engineering judgment, the AISC-358 (2016c) [15] and FEMA-355 (2000) [16] standards accept the application of box-column connections; if they are used with the continuity plate being attached to the internal faces of the column by complete penetration welding. Chen et al. (2004) [17] investigated the connection of the beam to the box-column by using the continuity plates inside the column. The results showed that most samples offered the expected performance. The plastic hinges were effectively moved away from the column face. However, the overall ductile behavior in some of the samples was not observed; this was mostly due to the brittle failure of the flange to the column welds as well as the brittle failure of the continuity plate to the column welds.

In general, the results of experiments and numerical analyses on both box and $\mathrm{H}$-shaped columns showed that the transfer of moment from the connection to the box-column is less than that to the H-shaped column. This behavior in moment transfer can be attributed to the out-of-plane deformation of flanges in the box-column (Kim and Oh 2007) [18]. Next, the studies of Saneei Nia et al. (2013, 2014a, b, c) [19-22] are addressed who examined the I-beam to box-column connections experimentally and numerically, as shown in Figs. 1 and 2. 
In their study, by performing six full-scale tests on WUF-W moment connections, they concluded that the plastic hinge was generated in the beam's predicted area near the connection. Nevertheless, the damage and deterioration did not occur in the columns, panel zones, continuity plates, web shear plates, and the beam web and flange connection to the column at the point of penetration welds. In all the tested samples, a minimum of 0.04 rad inter-story drift was observed without strength degradation, and of a $0.06 \mathrm{rad}$

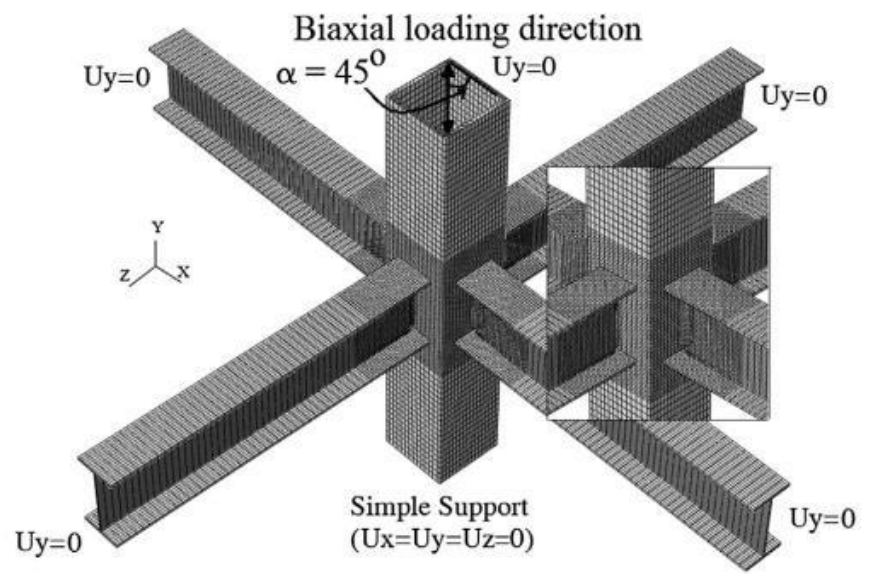

Fig. 1. 3D finite element model of the analytical specimen subjected to biaxial loading [19]

Song et al. (2015, 2016) [23] \& [24] investigated the behavior of double-angle bolted and unstiffened welded connections in square and tubular columns subjected to monotonic and cyclic loading following the SAC loading protocol, as shown in Fig.3. In this study, they argued that although the double-angle bolted connections are designed based on resistance to shear loads, the double-angle connections reduce damage subjected to cyclic loading. The column panel thickness at the panel zone significantly affects the rotation of the connection and stress distribution inter-story drift was occurred with less than $20 \%$ strength degradation. Also, two full-scale tests were performed for direct connection of beam with increased cross-section, in which the web shear plate was removed. The plastic hinge was directed away from the column face by increasing the beam's cross-section near the connection. The results indicated that their connection could be classified as a moment connection to a box-column in a special moment frame by providing the required inelastic rotation capacity.

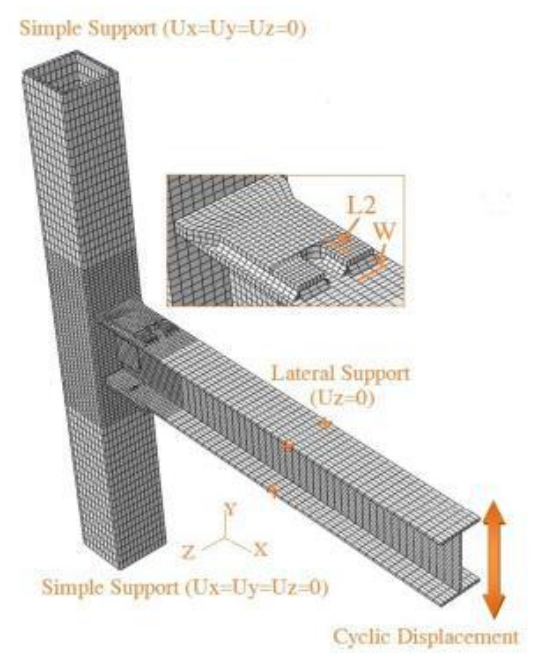

Fig. 2. 3D finite element model of the modified FP connection [22]

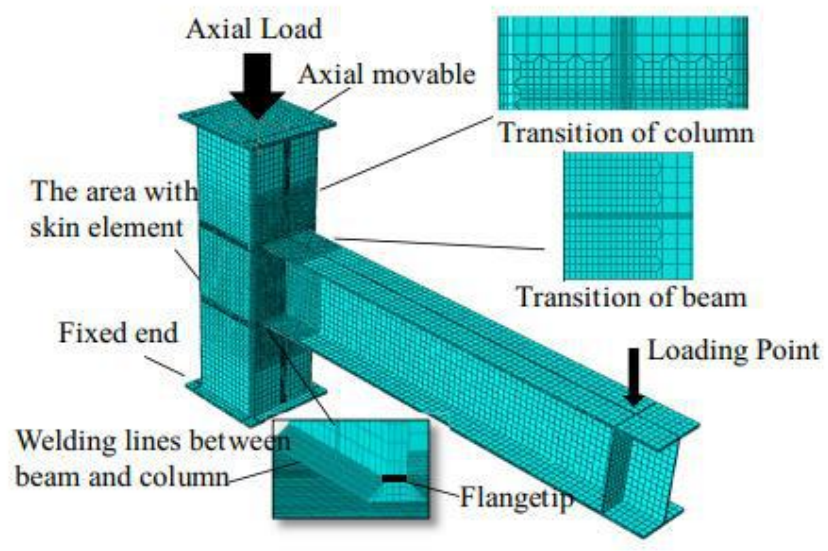

Fig. 3. Finite element modeling [23] 
Mirghaderi and Moradi (2006) [25], Mirghaderi et al. (2010, 2013) [26] \& [27] investigated the demands created in the panel zone and the continuity plates in the boxcolumns. Figs. 4 and 5 shows the demands established on all plates of this region were extracted in the limit state, and the stresses created on the plates were obtained by modeling the plates in finite element software. Their study stated that the von Mises stress in the plates with constant thickness, especially in the continuity plate, is higher in the biaxial bending than the uniaxial bending condition. Finally, they recommended that the thickness of the continuity plate be set about 1.4 times the beam flange thickness. Alostaz and Schneider recommended that the continuity plate thickness be at least half the beam flange thickness in H-shaped columns (Alostaz and Schneider 1996) [28]. a

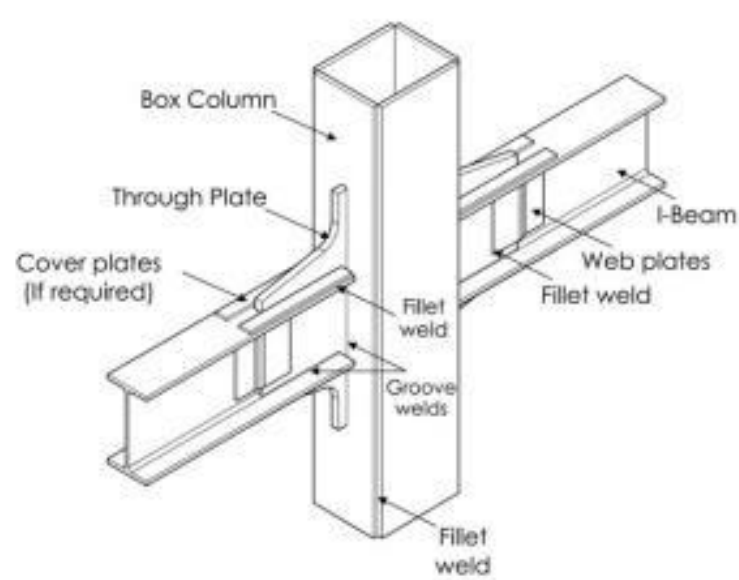

b

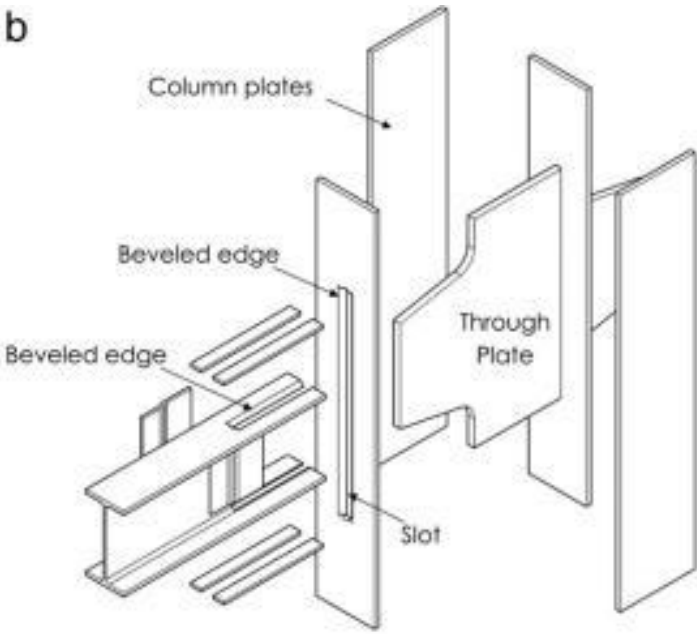

Fig. 4 The through plate moment connection: (a) Planar-form Configuration, (b) Planar-form Assembly. [26]

C

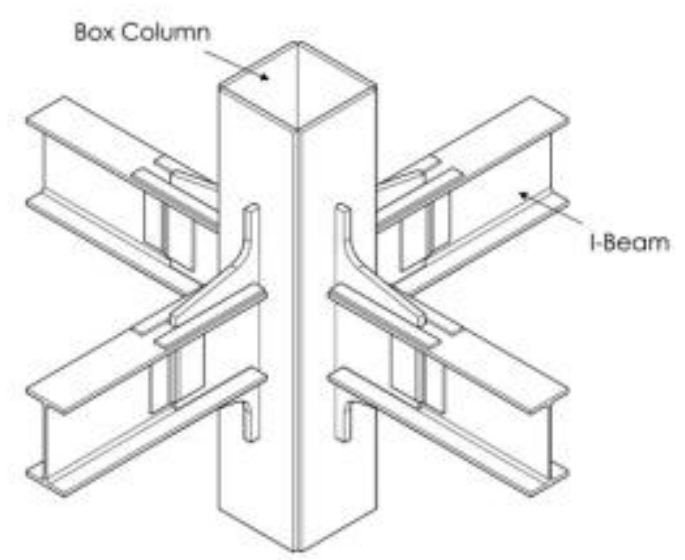

d

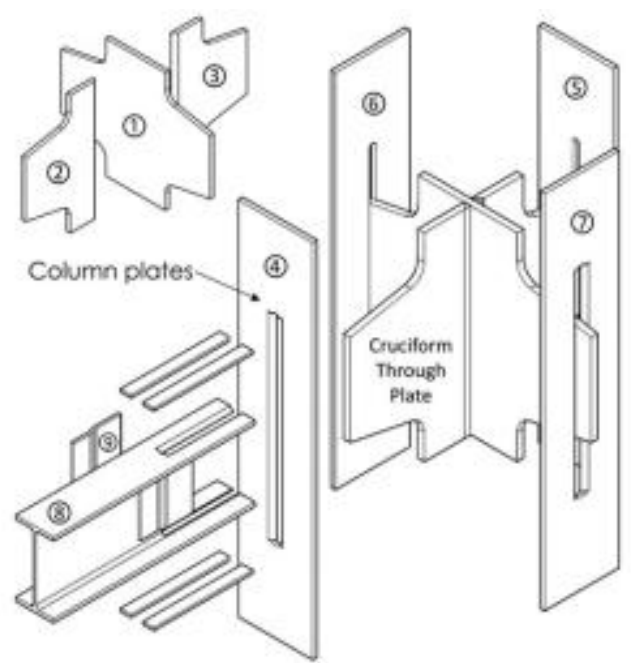

Fig. 5 The through plate moment connection: (c) Orthogonal-form configuration, (d) Step-by-step fabrication process (by assembly sequence number).[26]

Ghobadi et al. (2009) [29] utilized external T-stiffeners to improve the moment connections' seismic behavior in boxcolumns. In this research, the cyclic behavior of the proposed reinforced connection is studied numerically and experimentally. The results indicated that the T-stiffener's crack propagation is the dominant failure mode for all the samples, so that they referred to the stress concentration on the T-stiffener attached to the fixed connection. Moreover, numerical studies suggested that fillet welding used to connect the T-stiffener to the beam flange instead of penetration welding reduces the potential of internal cracking and crack propagation at the moment-resisting connection. 
M. Ghassemieh et al. (2021) [30] investigated the technical literature and seismic design provisions to design guidelines and recommendations related to the moment connections, and continuity plates are mainly developed for the $\mathrm{H}$-shaped and wide-flange columns. Thus, in this study, due to the significant use of IBBC connection, the seismic performance of two types of prequalified moment connections is investigated. For this reason, connections of 7 and 12 story special moment framed structures are selected as case studies. For each of the frames, the RBS and WUF-W welded connections were individually designed in three categories: light weight (light), middle weight (medium), and heavy weight (heavy) types. It is worth mentioning that the connections' classifications are based on the dimensions of the frames' sections designed in the study frames. The typical detailing of both connections is illustrated in Figs. 6 and 7. Then the connections were modeled in the finite element analysis software. The performance of the welded connections in the box-columns was investigated within the qualifying criteria of the code standards and the collapse conditions. Finally, the demand and energy levels of the moment connections subjected to the SAC loading protocols (1997) and ATC-24 loading protocols (1992) are compared in order to determine the impacts of those loading protocols.
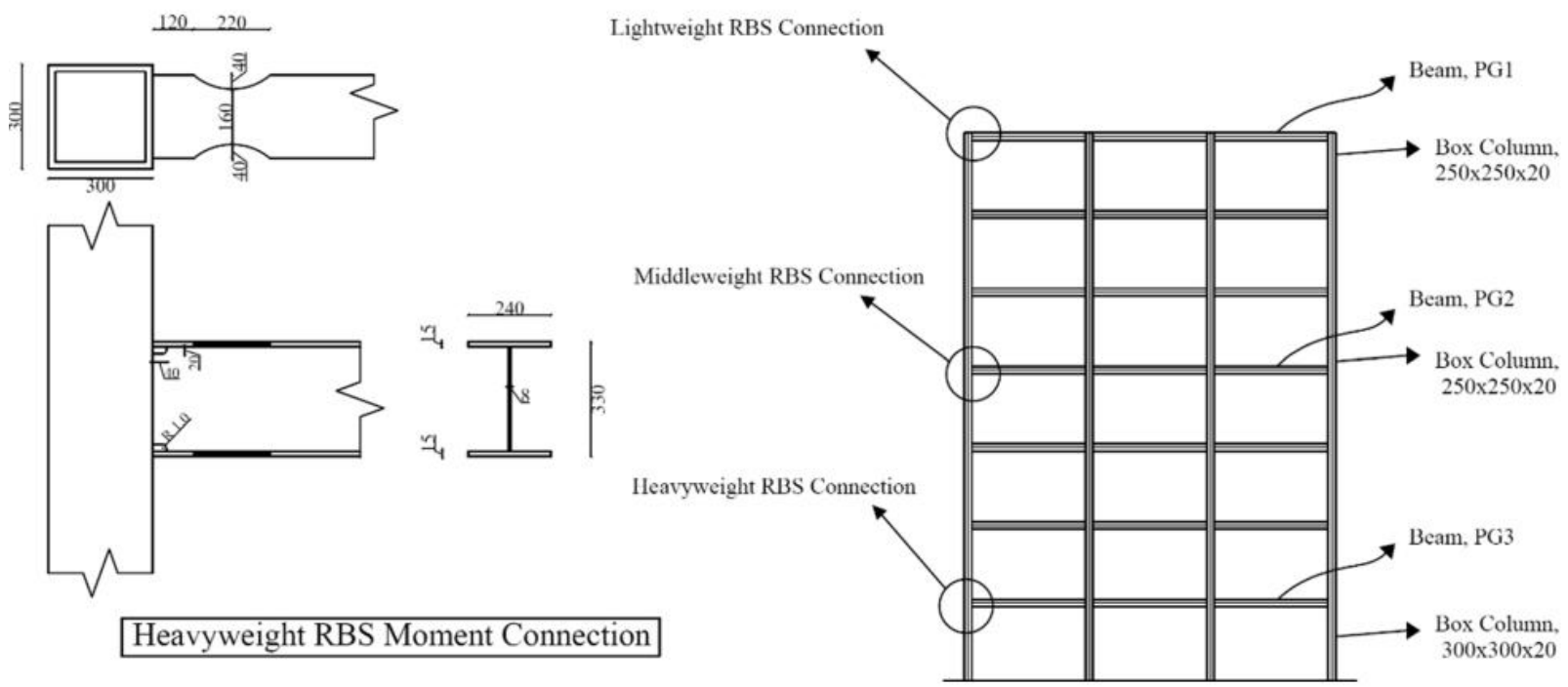

Heavyweight RBS Moment Connection

Fig. 6 Details of heavy RBS connection in 7-story structure (unit: $\mathrm{mm}$ )
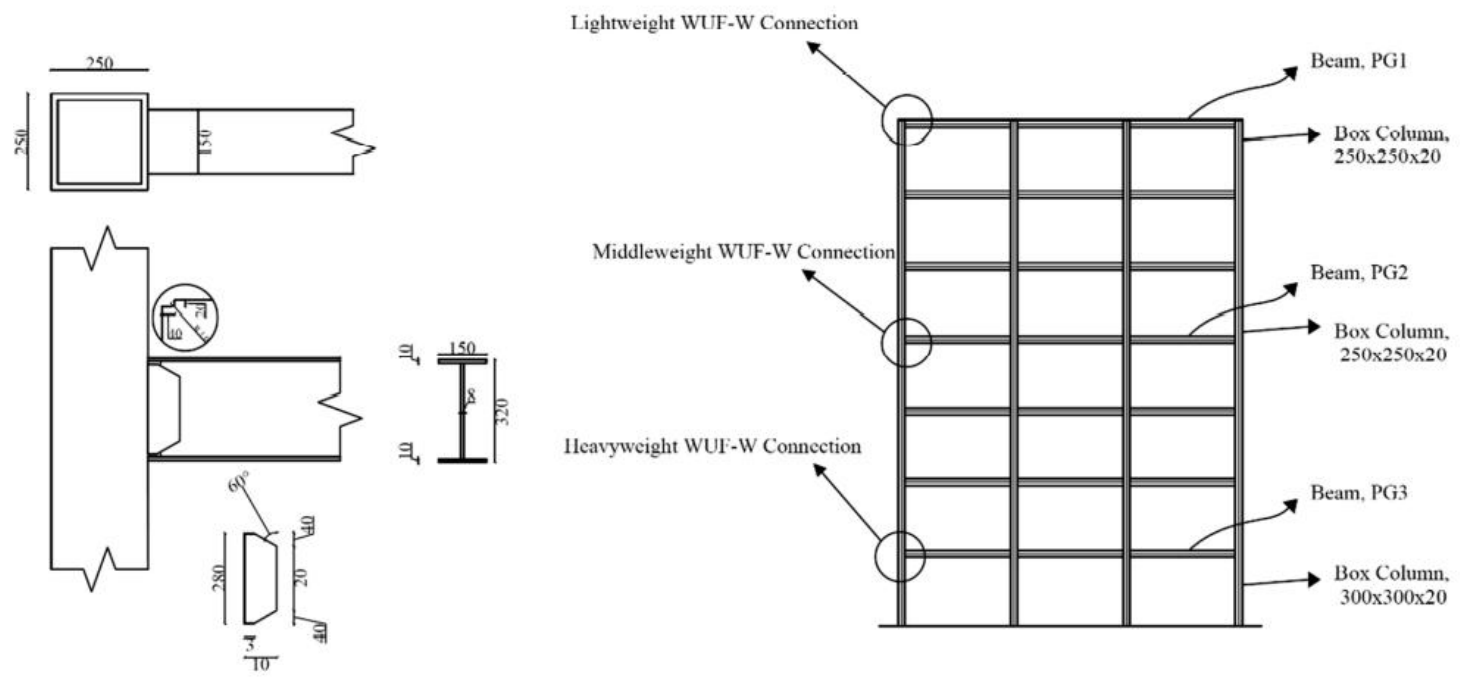

Lightweight WUF-W Moment Connection

Fig. 7 Details of light WUF-W connection in 7-story structure (unit: mm) 


\section{CONCLUSIONS}

The study until now was performed on analyzing and predicting the behaviour and the performance of the beam to box column connection under seismic load. Many researchers derived the expressions for deflection, ultimate moment, bearing capacity, energy-dissipation, Stiffness Degradation and many more. Some questions regarding the behaviour of the connection for moving the plastic hinge outside the joint and design requirements to achieve ductile failure. The optimization of the design for the proper combination of different stiffeners profile and type of failure to be provided is not yet completed. Though the provisions of codes that based on experimental results and finite element analysis of beam to box column connection, The relationship between the joint elements is still complex due to the nonlinear deformations to find possible solution for avoiding premature occurrences of brittle fracture in rectangular hollow section (RHS) column-to-I beam connections.

\section{REFERENCES}

[1] Plumier, A. (1990). New idea for safe structure in seismic zones. Belgium: IABSE symposium. Brussels.

[2] Yu, Q.S., Gilton, C.S., Uang, C.M. (1999). Cyclic response of RBS moment connections: Loading sequence and lateral bracing effects, Report No. SSRP 99-13. University of California at San Diego, La Jolla, CA.

[3] Pachoumis, D. T., Galoussis, E. G., Kalfas, C. N., \& Christitsas, A. D. (2009). Reduced beam section moment connection subjected to cyclic loading: experimental analysis and FEM simulation. Engineering Structures, 31, 216-223.

[4] Sophianopoulos, D. S., \& Deri, A. E. (2011). Parameters affecting response and design of steel moment frame reduced beam section connections: An overview. International Journal of Steel Structures, 11, 133-144.

[5] Hong, J. K. (2019). Sloped RBS moment connections at roof floor subjected to cyclic loading: analytical investigation. International Journal of Steel Structures, 19, 329-339.

[6] Lee, C. H., Jung, J. H., \& Kim, S. Y. (2019). Cyclic seismic performance of weak-axis RBS welded steel moment Connections. International Journal of Steel Structures, 19, 1592-1604.

[7] Engelhardt, M. D., Winneberger, T., Zekany, A. J., \& Potiraj, T. J. (1998). Experimental investigations of Dogbone moment connections. Engineering Journal, American Institute of Steel Construction, AISC, 35(4), 128-139.

[8] Engelhardt, M. D., Venti, M., Fry, G., Jones, S., Holliday, S. (2000). Behavior and design of radius cut reduced beam section connections. A draft report of SAC task. 7.07a. SAC Joint Ven.

[9] Gilton, C.S., Chi, B., Uang, C.M. (2000). Cyclic testing of RBS moment connections: Weak axis configuration and deep column effects. SAC report 00/23, SAC Joint Venture.
[10] Iwankiw, N. (2004). Seismic design enhancements and the reduced beam section detail for steel moment frames. Practice periodical on Structural Design and Construction ASCE, 9(2), 87-92.

[11] Kim, S. Y., Shin, K. J., Lee, S. H., \& Lee, H. D. (2016). Experimental investigation of beam-to-column connection with SHN490 steel under cyclic loading. International Journal of Steel Structures, 16, 1299-1307.

[12] AISC/ANSI 360-16. (2016b). Commentary on the specification for structural steel buildings. Chicago (IL): American Institute of Steel Construction, Inc.

[13] Han, S. W., Kim, N. H., \& Cho, S. W. (2016). Prediction of cyclic behavior of WUF-W connections with various weld access hole configurations using nonlinear FEA. International Journal of Steel Structures, 16, 1197-1208.

[14] Shin, J., \& Kim, J. (2017). Numerical and experimental study on welded and bolted steel beam-column connections subjected to cyclic loading. Journal of Earthquake and Tsunami, 11(4), 1750014.

[15] AISC/ANSI 358-05s2-14. (2016c). Prequalified connections for special and intermediate steel moment frames for seismic applications. Chicago (IL): American Institute of Steel Construction, Inc.

[16] FEMA 355. (2000). State of the art report on connection performance. Prepared by the SAC Joint Venture for the Federal Emergency Management Agency Management Agency. Washington, DC.

[17] Chen, C. C., Lin, C. C., \& Tsai, C. L. (2004). Evaluation of reinforced connections between steel beams and box columns. Engineering Structures, 26, 1889-1904.

[18] Kim, Y. J., \& Oh, S. H. (2007). Effect of the moment transfer efficiency of a beam web on deformation capacity at box column-to-H beam connections. Journal of Constructional Steel Research, 64, 24-36.

[19] Saneei Nia, Z., Ghassemieh, M., \& Mazroi, A. (2013). WUFW connection performance to box column subjected to uniaxial and biaxial loading. Journal of Constructional Steel Research, 88, 90-108.

[20] Saneei Nia, Z., Ghassemieh, M., \& Mazroi, A. (2014a). Panel zone evaluation of direct connection to box column subjected to bidirectional loading. The Structural Design of Tall and Special Building, 23, 833-853.

[21] Saneei Nia, Z., Mazroi, A., Ghassemieh, M., \& Pezeshki, H. (2014b). Seismic performance and comparison of three different I beam to box column joints. Earthquake Engineering and Engineering Vibration, 13(4), 717-729.

[22] Saneei Nia, Z., Mazroi, A., \& Ghassemieh, M. (2014c). Cyclic performance of flange-plate connection to box column with finger shaped plate. Journal of Constructional Steel Research, 101, 207-223.

[23] Song, Q. Y., Heidarpour, A., Zhao, X. L., \& Han, L. H. (2015). Performance of unstiffened welded steel I-beam to hollow tubular column connections under seismic loading. International Journal of Structural Stability and Dynamics, 15(1), 14500331-145003323.

[24] Song, Q. Y., Heidarpour, A., Zhao, X. L., \& Han, L. H. (2016). Performance of double-angle bolted steel I-beam to hollow square column connections under static and cyclic 
loadings. International Journal of Structural Stability and Dynamics, 16(2), 14500981-145009820.

[25] Mirghaderi, S.R., \& Moradi, M. (2006). Seismic behavior of panel zones in beam to column connections with non-planner webs in moment resisting steel frames. In: 4th International conference on earthquake engineering; Taiwan; 2006.

[26] Mirghaderi, S. R., Torabian, S., \& Keshavarzi, F. (2010). Ibeam to box-column connection by a vertical plate passing through the column. Engineering Structures, 32, 2034-2048.

[27] Mirghaderi, S.R., Ghassemieh, M., Seifan, F. (2013). Limited examination of panel zones and continuity plates demand in I-beam to box-column connection under biaxial bending. In: 4th National conf. steel \& structure; 25-26 December, Tehran, Iran.

[28] Alostaz, Y., \& Schneider, S. (1996). Analytical behavior of connections to concrete-filled steel tubes. Journal of Constructional Steel Research, 40, 95-127.

[29] Ghobadi, M. S., Ghassemieh, M., Mazroi, A., \& Abolmaali, A. (2009). Seismic performance of ductile welded connections using T-stiffener. Journal of Constructional Steel Research, 65, 766-775.

[30] M. Ghassemieh, M. Hassani Sokhtesaraei \& S. R. Mirghaderi (2021). The Behavior of Welded Moment Connections in Box-Columns and Investigating Applied Demands for Different Cyclic Loading Protocols. International Journal of Steel Structures, 21(2):455-474 